\title{
A Rare Case of Congenital Megaureter in Adult with Classical Presentation
}

\author{
Aasmitha B, Seetha Pramila VV*, Rachana R, Prashanth J and Shukla AK \\ Department of Radiodiagnosis, Raja Rajeswari Medical College, India
}

"Corresponding author: Seetha Pramila VV, Professor, Department of Radiodiagnosis, Raja Rajeswari Medical College, Bengaluru, India, Tel: +91-9986377214; E-mail: varadaseetha@gmail.com

Received: September 05, 2018; Accepted: September 19, 2018; Published: September 21, 2018

\begin{abstract}
Introduction: Congenital megaureter is a condition usually diagnosed in neonates and children; its primary presentation in adults is rare. Spontaneous resolution occurs in over half of all affected children, and this is hypothesized to occur as a result of the ureterovesical junction (UVJ) maturation and growth. When this condition does present in adults, it typically does so during the third or fourth decade, and unilateral disease, most often left-sided is more common than bilateral disease.

Presentation of Case: A forty five year old female patient presented with recurrent attacks of left ureteric colic since 5 months. On examination, abdomen was soft and non-tender. Patient was referred for Contrast Enhanced Computed Tomography (CECT) KUB, which showed left sided megaureter and delayed excretion of contrast with maximum diameter of $4 \mathrm{~cm}$ and left hydronephrosis. The patient then underwent Magnetic Resonance (MR) urography which confirmed the CECT KUB findings. Patient was then advised to undergo ureteroplasty.
\end{abstract}

Conclusion: Primary presentation of congenital megaureter in adults is rare. It is expected that leaving the underlying abnormality intact may pose the patient to the stone formation and urinary tract infection causing persistence of symptoms.

Keywords: Congenital megaureter; Computed Tomography; Ureterovesical junction

\section{Introduction}

Initially described by Caulk in 1923, congenital megaureter is a condition usually diagnosed in neonates and children; its primary presentation in adults is rare [1]. Spontaneous resolution occurs in over half of all affected children, and this is hypothesized to occur as a result of the ureterovesical junction (UVJ) maturation and growth [2-4].

Diagnostic criteria include: dilated ureter, absence of vesicoureteral reflux, absence of infravesical obstruction and absence of distal ureteral obstruction [5]. When this condition does present in adults, it typically does so during the third or fourth decade, and unilateral disease, most often left-sided is more common than bilateral disease [6,7].

Citation: Aasmitha B, Seetha Pramila VV, Rachana R, et al. A Rare Case of Congenital Megaureter in Adult with Classical Presentation. Clin Case Rep Open Access. 2018;1(1):106.

(C)2018 Yumed Text. 


\section{Presentation of Case}

A forty five year old female patient presented with recurrent attacks of left sided flank pain since 5 months, colicky type and radiating to the groin. She had no complaints of fever, haematuria or burning micturition. On examination, abdomen was soft and non-tender. Urine examination was not significant. Ultrasonography of abdomen and pelvis done outside revealed left gross hydroureteronephrosis. Patient was then suggested to undergo CECT KUB for further evaluation. CT abdomen revealed left sided megaureter with a maximum diameter of $4 \mathrm{~cm}$ (FIG. 1). Post contrast CT KUB shows delayed excretion of contrast (FIG. 2a and 2b). Patient was then suggested to undergo MR urography for further evaluation. MR urography shows left sided megaureter (FIG. 3).

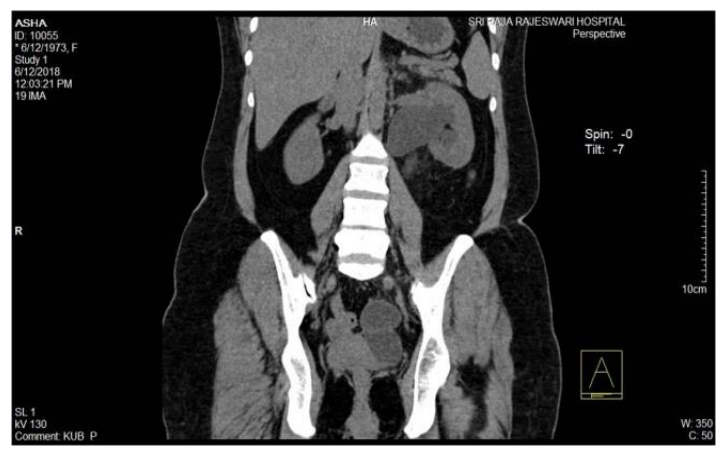

FIG. 1. CT KUB plain image coronal section showing left sided megaureter.

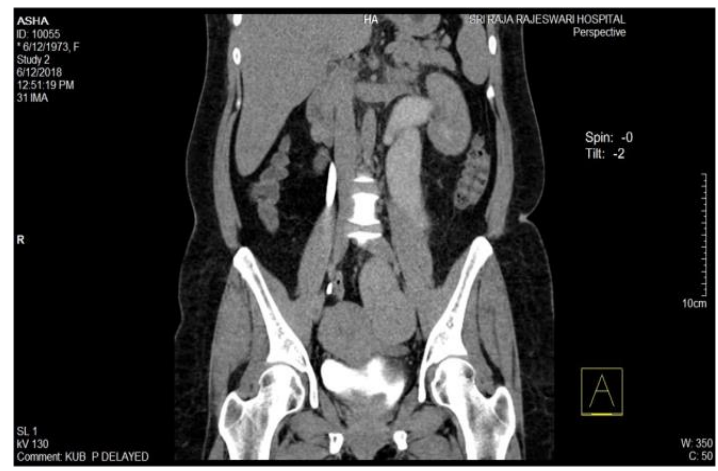

FIG. 2a. CT KUB post contrast delayed images in coronal section showing left sided.

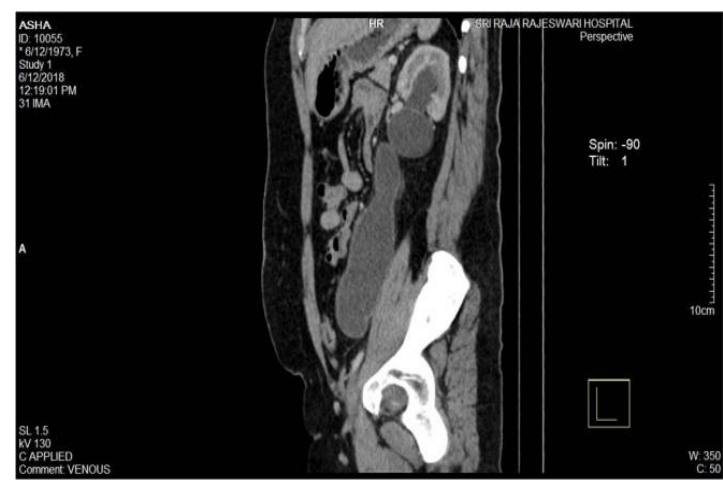

FIG. 2b. CECT KUB saggital view showing megaureter. 


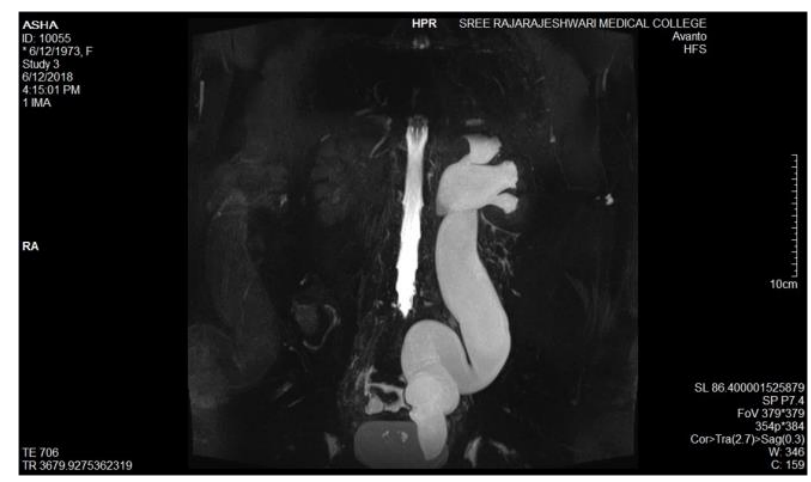

FIG. 3. MR urography showing left sided megaureter.

\section{Discussion}

The current belief is that primary obstructive megaureter (POM) presents primarily in adults when the congenital abnormality does not cause symptoms or illness and is not seen via an imaging study performed in children. Spontaneous regression fails to occur, yet patients remain asymptomatic through childhood and into their adult years. Eventual symptoms that may occur include: urinary tract infections, renal parenchymal damage and recurrent stone formation. They may be asymptomatic or present with flank pain, recurrent urinary tract infection (UTI), and hematuria in the symptomatic situations. Pain is the most common presenting symptom [8]. In mild cases, there is a $2 \mathrm{~cm}-3 \mathrm{~cm}$ fusiform lower ureteral dilation just proximal to the tapered extravesical distal segment [9]. With increasing severity, the ureter dilates more proximally and involves the collecting system. In extreme cases, there is significant hydronephrosis, and loss of the renal parenchyma leading to the impaired renal function. The characteristic criteria for the diagnosis of POM are; absence of vesicoureteral reflux (VUR), absence of obstruction in the infra-vesical area, and absence of secondary causes of lower ureteral obstruction [10,11]. The adult presentation of POM is in the third or fourth decades of life, and unilateral involvement is more common than bilateral disease.

The condition is usually seen in the left side with the male predominance [12,13]. In a large reported series of 55 adults with symptomatic POM, Hemal et al. [14] identified 20 patients (36\%) to have urinary tract stones. The rate of synchronous renalureteral unit stones was 5.5\% [14]. Associated anomalies can be found with POM such as ureteropelvic junction obstruction, horseshoe kidney, megacalicosis, megalourethra, megacystis, and contralateral renal atrophy. From these anomalies, contralateral renal atrophy was the most common, and was found in $9 \%$ of cases [14]. Most of the stones were located in the ureter; only 3 of the 55 patients $(5 \%)$ had isolated renal calculi. Large stones can develop in the dilated portion of the ureter due to urinary stasis. Delakas et al. [15] described an adult patient with POM who developed a $12 \mathrm{~cm}$ isolated ureteral stone within the dilated portion of involved ureter. Extracorporeal Shock Wave Lithotripsy (ESWL), ureteroscopy, ureteral meatotomy and stenting, and percutaneous nephrostomy are non-invasive or less invasive techniques that sometimes are needed in the management of POM or POM related stones [14]. Rosenblatt et al. [16] reported two cases of adult POM that presented with urolithiasis. Due to small stone sizes, they just treated the stones without surgical repair of the underlying megaureter. 
www.yumedtext.com | September-2018

\section{Conclusion}

Based on the best of our knowledge primary presentation of congenital megaureter in adults is a rare occurrence. It is not very difficult to diagnose megaureter. High clinical suspicion and relative investigations are required to rule out obstruction. Micturating Cysto Urethrogram(MCU) is the investigation of choice to rule out reflux and USG/CT imaging is done to rule out obstruction.

\section{REFERENCES}

1. Caulk JR. Megaloureter: The importance of the ureterovesical valve. J Urol. 1923;9:315-9.

2. Pitts Jr WR, Muecke EC. Congenital megaloureter: a review of 80 patients. J Urol. 1975;111(4):468-73.

3. Oliveira EA, Diniz JS, Rabelo EA, et al. Primary megaureter detected by prenatal ultrasonography: conservative management and prolongad followup. Int Urol Nephrol. 2000;32(1):13-8.

4. Domini M, Aquino A, Pappalepore N, et al. Conservative treatment of neonatal primary megaureter. Eur J Pediatr Surg. 1999;9(6):396-9.

5. Khoury A, Bagli DJ. Reflux and Megaureter. In: Wein AJ, Kavoussi LR, Novick AC, et al., editors. CampbellWalsh Urology. 9th ed. Philadelphia: Elsevier Inc; 2007. 3467-81 p.

6. Dorairajan LN, Hemal AK, Gupta NP, et al. Primary obstructive megaureter in adults: need for an aggressive management strategy. Int Urol Nephrol. 1999;31(5):633-41.

7. Hanna MK, Wyatt JK. Primary obstructive megaureter in adults. J Urol. 1975;113(3):328-35.

8. Hamilton S, Fitzpatrick JM. Primary non-obstructive megaureter in adults. Clin Radiol. 1987;38(2):181-5.

9. Pfister RC, McLoughlin AP, Leadbetter WF. Radiological evaluation of primary megaureter. Radiology. 1971;99:503-10.

10. Atala A, Keating MA. Vesicoureteral reflux megaureter and ureteric reimplantation. In: Walsh PC, Retik AB, Vaughan Jr. ED, et al., editors. Campbell's urology. 6th ed. Philadelphia: WB Saunders, USA; 1992. 1708-33 p.

11. Kelalis PP, King LR, Belman AB, et al. Clinical paediatric urology. Philadelphia: WB Saunders, USA; 1976. 266-80 p.

12. Dorairajan LN, Hemal AK, Gupta NP, et al. Primary obstructive megaureter in adults: need for an aggressive management strategy. Int Urol Nephrol. 1999;31(5):633-41.

13. Hanna MK, Wyatt JK. Primary obstructive megaureter in adults. J Urol. 1975;113(3):328-35.

14. Hemal AK, Ansari MS, Doddamani D, et al. Symptomatic complicated adult and adolescent primary obstructive megaureterindications for surgery: analysis, outcome, and follow-up. Urology. 2003;61(4):703-7.

15. Delakas D, Daskalopoulos G, Karyotis I, et al. Giant ureteral stone in association with primary megaureter presenting as an acute abdomen. Eur J Radiol. 2002;41(2):170-2.

16. Rosenblatt GS, Takesita K, Fuchs GJ. Urolithiasis in adults with congenital megaureter. Can Urol Assoc J. 2009;3(6): E77-E80. 